\title{
Selecting Among Acquitted Defendants: Procedural Choice vs. Selective Compensation
} Comment

\author{
Ansgar Wohlschlegel \\ Portsmouth Business School
}

Summary of Discussed Paper Being charged with a crime often results in social stigma even if the defendant has been cleared of the charges. For instance, an employer may anticipate that a criminal's expected productivity is lower than an average person's, or a landlord may anticipate problems when letting a house to a criminal. Since the proportion of criminals even among acquitted defendants is larger than that among the general population, defendants will earn lower wages and pay higher rent even after acquittal.

In a recent paper, Daughety and Reinganum (2014) show that the Scottish Verdict, in which juries can, based on the strength of the evidence, acquit defendants either as 'not guilty' or as 'not proven', delivers a more precise signal to society on the defendant's true guilt than the standard rule, and thus implies that truly innocent defendants are less likely to be stigmatised. Based on this result, Daughety and Reinganum (2016, henceforth DR) analyse two different ways of implementing the Scottish verdict within the U.S. criminal justice system, one in which defendants can decide between being adjudicated under the standard rule and under the Scottish verdict, and another one in which juries may award compensation to acquitted defendants if the evidence against them is particularly weak (selective compensation). They find that, although only innocent defendants are better off under the Scottish verdict, even guilty defendants would opt for it in order to imitate the innocents. Furthermore, selective compensation permits less accurate informal punishment than the Scottish verdict (unless prosecutors are not held responsible for compensation) but might be better implementable in practice.

In the following, I will discuss three ways of extending DR's analysis: allowing for risk-averse defendants, considering the social cost of informal punishment even of truly guilty defendants, and the protection of a defendant's privacy as an alternative means of avoiding informal punishment of truly innocent defendants. 
Risk Aversion A practical implication of DR's results is that, if the legal system does not allow for imposing the Scottish verdict on defendants, allowing them to decide over its application is equivalent, since risk-neutral, truly innocent defendants strictly prefer the Scottish verdict over the standard rule. Hence, a defendant who decides against the Scottish verdict can be inferred to be truly guilty. However, while a truly innocent defendant's expected payoff is higher under the Scottish verdict, so is its variance, since even a truly innocent acquitted defendant may end up being labeled not proven and getting a higher informal punishment than under the standard rule. Hence, a risk-averse innocent defendant may still prefer the standard rule, thus rendering a choice of the standard rule a worthwhile option for guilty defendants. As a consequence, the standard rule would be used excessively under such a regime, making the alternative regime of selective compensation a potentially more attractive legislative option.

Social Cost of Stigmatising Truly Guilty Defendants Whereas DR evaluate legal scenarios based on the accuracy of the imposed informal sanctions, an interesting avenue for future research is to explicitly analyse the effects of these legal scenarios on social welfare. Recall that the main motivation for DR's paper is to reduce informal punishment of truly innocent defendants, which is reflected by DR's use of the misclassification loss to evaluate legal scenarios. However, there may also be substantial welfare loss associated with stigmatising truly guilty defendants, as Funk (2004) and Mungan (2014) have stressed: For instance, if their benefit from legal activities falls due to stigma, they are more likely to recidivate. Taking the social costs of this consequence of social stigma into account may yield quite different policy conclusions.

To illustrate this point, consider an extension of the model in which there is a probability $\alpha$ that a truly guilty defendant commits another crime, which depends on the wage that the defendant earns after acquittal, and let the social welfare loss caused by this crime be $L$. In accordance with the literature on stigmatisation of criminals ${ }^{1}$ and DR's assumption that informal punishment is proportional to the outside observer's belief that the defendant is truly guilty, let $\alpha(\mu(G \mid y))$ be an increasing function of these beliefs for every jury decision $y$. Suppose furthermore that the defendant has been acquitted, and let $h_{n g}$ be the probability of a not-guilty verdict under the Scottish rule conditional on being acquitted. Then the expected social loss due to subsequent crimes committed by an acquitted defendant under the Scottish verdict is

$$
S=\left[h_{n g} \mu(G \mid n g) \alpha(\mu(G \mid n g))+\left(1-h_{n g}\right) \mu(G \mid n p) \alpha(\mu(G \mid n p))\right] L
$$

\footnotetext{
${ }^{1}$ Rasmusen (1996) and Mungan (2014) show that wages in a competitive labour market will be increasing in the employers' beliefs about whether the employee is a criminal.
} 
Note that $h_{n g}, \mu(G \mid n g)$ and $\mu(G \mid n p)$ are increasing in $\gamma_{n g}$. Furthermore, (A.2b) and (A.2c) in DR imply that, as $\gamma_{n g}$ approaches $\gamma_{g}$ (or 0 , respectively), the situation converges to the standard rule, in which case $\mu(G \mid n g)$ (or $\mu(G \mid n p)$, respectively) approaches $\mu(G \mid a)$ and $h_{n g}$ approaches 1 (or 0 , respectively). If the jury is instructed to choose the evidence threshold $\gamma_{n g}$ so as to minimize $S$, then, depending on the functional form of $\alpha\left(\right.$.), it may well be the case that this will be achieved by choosing $\gamma_{n g}=\gamma_{g}$ (or, equivalently, $\gamma_{n g}=0$ ), i.e., by the standard rule.

Intuitively, my assumption that only truly guilty defendants would commit a crime again implies that the crime rate only depends on the informal punishment of truly guilty defendants. DR's analysis implies that truly guilty defendants under either way of implementing the Scottish verdict are worse off than under the standard rule. Hence, if $\alpha($.$) is at least not too concave, social costs from repeat offending are minimized under$ the standard rule.

Of course, a full welfare analysis would also require taking into account social benefits of employers being able to observe more accurately whether their potential employees are truly innocent or guilty, such as, for instance, incentives for truly innocent people to invest in human capital. Furthermore, much of the above analysis was driven by the assumption that truly innocent defenders would not become criminals even after being socially stigmatised. Hence, a useful task for future research is to derive hypotheses regarding the areas of law in which these assumptions that favour the standard rule are more or less likely to hold.

Privacy Law A final suggestion of how to extend DR's analysis is to consider other ways of reducing the social cost of stigmatising innocent defendants. For instance, many countries have introduced strong privacy laws that protect personal details of most acquitted defendants. ${ }^{2}$ In Germany, even some of the convicted defendants are protected by this law, since only convictions above a certain threshold of the formal sanction are included in the criminal record. This kind of anecdotal evidence is in line with the theoretical results in this area such as that of Mungan (2014), who argues that convicts guilty of low-harm (high-harm) crimes should always (never) be protected from social stigma, whereas convicts guilty of crimes with intermediate levels of harm should be given the opportunity of expunging at a cost. Given these differences across countries and the aforementioned disadvantages of making informal sanctions more efficient, an interesting research question would be to derive testable hypotheses as to whether privacy law or the Scottish verdict is socially preferable, and how this comparison depends on a country's

\footnotetext{
${ }^{2}$ The few exceptions in which the identity of a defendant becomes publicly known already during the trial in these countries typically involve defendants or crimes of extraordinary public interest.
} 
legal environment.

\section{References}

Daughety, A. F., And J. F. Reinganum (2014): "Informal Sanctions on Prosecutors and Defendants and the Disposition of Criminal Cases," Discussion paper.

(2016): "Selecting Among Acquitted Defendants: Procedural Choice vs. Selective Compensation," Journal of Institutional and Theoretical Economics, 172(1).

Funk, P. (2004): "On the effective use of stigma as a crime-deterrent," European Economic Review, 48(4), 715-728.

Mungan, M. C. (2014): "On the Sealing of Criminal Records, Stigma and Deterrence," Discussion Paper 709, FSU College of Law.

Rasmusen, E. (1996): "Stigma and self-fulfilling expectations of criminality," Journal of Law and Economics, 39(2), 519-543. 